\title{
9. ASIAN AUSTRALIAN STUDIES IN ASIA: CHINA AND JAPAN
}

\section{David Carter}

T

his essay rests on two assumptions. First, that 'cultural diplomacy' is a good thing. Second, that 'Australian studies' have a significant role to play in cultural diplomacy. Both points, of course, need elaboration and qualification. In providing this I want to talk about the situation of Australian studies in China and Japan, their strengths but also weaknesses in having any significant influence on 'how others see us'.

By cultural diplomacy, I mean the process of deliberately - that is, as a matter of policy and supported by government money and infrastructure — 're-purposing' Australian cultural products, whether books, art, dance, theatre, craft, music or their creators, as a means of telling the rest of the world something about Australia, past, present and future. Cultural diplomacy by definition means working within a government agenda, and for that reason the idea often produces a negative response from those in the academy, especially those at the 'cultural' end of the academy. This reaction, I believe, is often little more than a residual form of late-romantic 'culturalism' the belief that culture transcends the more sordid domains of market-place or policy-making.

My argument is that we must take on board the positive case for engagement with cultural diplomacy and that those 
I might call 'cultural academics' or 'cultural intellectuals' have an important role to play in shaping how the nation thinks about and projects itself and in shaping the reception of these projections outside Australia. Having said that, one of the key intellectual and cultural benefits of engaging in this process is that the reception never can be determined or shaped definitively; the process will always involve conflicting perceptions and frameworks and we should expect to be rudely reminded at times just how Australia looks from elsewhere.

Although we will always want to reserve the right to be sceptical of any (and every) government's immediate motives — the resistance and debate is part of the process — the agenda and procedures of cultural diplomacy are normally broad enough to enable all sorts of engagements to occur within their brief. And they are mostly operated by 'arm's-length' bodies. Most of us, I would guess, could find ways of taking on board the desire of government to project Australia abroad as a sophisticated, multicultural, democratic nation (according to the present rhetoric). After all, talking publicly about racism and intolerance would be one mark of such a society — at least in my reading.

In other words, we need to talk to government, to work with government, to lobby government, not to walk away and accuse government for, well, being government.

What about the role of Australian studies? Side-stepping for the moment the question of just what Australian studies are, promoting the study of Australia at all levels of the curriculum and supporting serious research on Australia overseas seems to have a crucial role not just in producing 'foreign friends' who think better of us, but more importantly, in furthering the process of 'Asianising Australia'. I share Stephen FitzGerald's line on this, that 'Asianising Australia' in one sense just means 'Australianising Australia' - coming to a fuller understanding of Australia's own history and its place in the world. ${ }^{1}$ By the same token, by 'Asianising Australia' I mean the process of enmeshing Australia into regional and comparative perspectives, so that it becomes part of the picture, always within the frame, when 
models are sought, comparisons made and so forth. In fact, in this sense I wouldn't mind all that much being accused of wanting to 'Australianise Asia'.

Although I will argue against promoting Australian studies simply under the rubric of area studies (though I will if I have to), I do think there are advantages in promoting something explicitly called 'Australian studies' rather than just relying on the diffusion of Australian content or methodologies across the curriculum. This has strategic advantages — not least for teachers and researchers overseas within their own institutions - and is significant in the process of working with government. The key is not to define Australian studies narrowly or to erect high walls around the area but instead, as I will explain later, to see it as a vehicle for interdisciplinarity, methodological innovation, comparative studies and internationalisation. Later I'll be raising the issue of the lack of serious research on Australia from overseas; while this might be happening in specific areas such as foreign policy, economics or the environment, those much more slippery areas such as culture, society, politics and history, those that provide a deep, contextualised understanding, need the kind of framing that something like Australian studies can provide.

I also don't mind being accused of ignoring Europe and North America. In a sense, while it is nice to see Australian studies centres sprouting up from London to Moscow, I don't think Australian studies matter in quite the same way outside Asia or the Asia-Pacific region (and by that I mean 'matters to us' here in Australia and 'matters to them' in the region). This is partly because a more or less shared tradition of academic practice and research protocols means that Australian studies in Europe and North America can, as it were, look after themselves (in an intellectual sense if not in terms of funding or infrastructure support); and also partly because the consequences for Australia are less significant. To put it another way: who cares what the English think of Australia? I do care what the Chinese and Japanese think (and what the Americans think — but that's another argument). 
I'm not going to attempt to describe what Chinese and Japanese Australianists think of Australia — that's a fascinating topic in its own right and one which others have researched (see Masayo Tada's paper). Instead I want to talk more about the programs of support from the Australian side for Australian studies in China and Japan - what's been done well, where the shortcomings lie and what might be done in the future. I will also make some remarks about how we might conceive of Australian studies in order for it to work most effectively in the region.

The readiest comparison to hand for Australian studies abroad is Canada and the Canadian Government's support of Canadian studies overseas. Last time I researched, a few years back, it appeared that the Canadian Government was spending about seven million Canadian dollars annually on programs supporting Canadian studies overseas, largely through their equivalent of our Department of Foreign Affairs and Trade (DFAT). This was seen to be a central part of the external affairs portfolio - with, it is true, some of the disadvantages as well as the many advantages of being centralised and bureaucratically integrated. As many will be aware, the Canadian Government supports an extensive program of grants and fellowships for overseas students and academics wishing to undertake Canadian studies and to teach and research Canada from elsewhere. Those of us working in Australian studies overseas are all too familiar with the question, why doesn't the Australian Government have a scheme like the Canadian Government?

Some quick calculations suggest that the Australian Federal Government spends a long way short of $\$ 1$ million on Australian studies overseas, and that's including estimates for permanent staff salaries. There is one important exception to this statement which I'll come back to later. Whatever the exact amount is, more than half of it would be directed towards China and Japan - a correct bias, I think, even if the amounts are relatively small. Of course, if we add in other agencies involved in cultural diplomacy - the Australia Council, the 
Australian International Cultural Council and Asialink, for example - the budget grows. But the dedicated Australian studies budget remains small.

We must be thankful for DFAT or rather for the bilateral bodies that manage the Australian studies programs: the Australia-China Council, the Australia-Japan Foundation and their counterparts for India, Indonesia and Korea.

At this point in time, the federal department responsible for education - DEST - does nothing at all, a fact we notice because in the mid-1990s, for a short time before and a very short time after the election of the present Federal Government, the Department of Education (DEETYA as it was then called) had a dedicated program and a federal committee of bureaucrats and academics established to oversee a program for Australian studies offshore - and its focus was almost entirely on Asia. ${ }^{2}$

The outcome of that program, under former Ministers Vanstone and Kemp, was a series of valuable country reports that have never been made public, a few one-off, short-term projects, all long gone, and two $\$ 5$ million allocations to two overseas Australian studies centres: yes, you guessed it, one in London and one in Washington. These weren't straight-out gifts - as I understand it, the centres get to live off the interest of the endowments. Still, the priorities were revealing. (This is the important exception I mentioned earlier.)

Let me summarise briefly the kinds of support provided for Australian studies in China and Japan. These are the two most mature of the Australian studies networks overseas. There are two ways to tell the story of Australian studies in China and Japan - a 'good news' story and a 'bad news' story. Both are valid but depend upon the framework or perspective we adopt. The former shows a high level of achievement built on small resources and commitment from the Australian side. The latter tells a story of minimal 'high level' achievement, especially in the area of top-quality research about Australia. I'll begin with the good news. 


\section{China}

The Australia-China Council (ACC) supports 15 Australian studies centres at last count, from Guangzhou to Inner Mongolia. These vary greatly - some are not much more than a single academic staff member, a title on the door and a 'trophy' shelf of book gifts from the Australian Government or visiting academics. Others have Masters-level teaching programs and staff engaged in research; the Academies of Social Science in Beijing and Shanghai are full research institutions although Australia competes for attention with many other nations.

There are other programs as well operated by the ACC: support for buying resources, book and translation awards; support for the Chinese Australian Studies Association and its biennial conference; and, most significant perhaps, a scheme of fellowships and scholarships enabling Chinese academic and graduate students to spend time in Australia, usually for six weeks to a few months. These are competitive, based on academic merit and the strength of a research proposal.

Trends in the ACC support for these programs are perhaps indicative of trends in government more generally. Increasingly, funding support is performance- and/or projectbased rather than recurrent funding - i.e. the centres must now make a claim to competitive project funding rather than expect to receive regular funding as a matter of course. The management of the whole 'Australian Studies in China' program has recently been put out to tender - in effect, for outsourcing - and here I must declare a conflict of interest, as the Australian studies centre which I direct has recently been announced as the successful tender.

If this sounds like economic rationalism there are good reasons behind these shifts, too: the shift to competitive project funding is designed to focus on performance and track record in general but also, more specifically, to give a much greater emphasis to research output. Along with the Japanese perhaps, Chinese Australian studies are probably the only network mature enough to benefit from this kind of shift at present. 
The majority of the Chinese Australian studies centres began in English or foreign-language departments which meant some bias until recently towards literary studies or 'cultural' and historical studies with something of an over-reliance on literary texts. This has shifted in recent times with more research being done into indigenous issues, multiculturalism, environmental issues, media, politics and so forth. I thought it a positive sign at the most recent Chinese Australian Studies Association conference, at Anhui University in Hefei in 2002, that I could hear a paper on Australian sewerage systems as well as papers on David Malouf, media ownership or mateship.

Given this past, Australian studies in China have been largely an English-language affair. The majority of papers at conferences have been delivered in English - a great boon to those of us struggling with beginner's Mandarin - and most courses are taught within English departments and often in English. Graduate students tend to be citizens of the Englishlanguage electronic world and, increasingly, are tuned in to global research agendas. While the dominance of English has, at least in theory, meant more direct access by Chinese students and researchers to English-language sources, and more access for Australians to Chinese Australian studies materials in English, it has also reinforced some limits on the building of Australian studies as an interdisciplinary enterprise and limited its potential influence across the universities and research centres. One of the biggest difficulties facing researchers in China is not just finding the resources for research, not just getting it published, but getting any reasonable kind of distribution or circulation of published research. Australian studies remain rather isolated, in an enclave, often relying on the heroic efforts of an individual or two in an institution, rather than being part of an academic or intellectual mainstream (although, as I will have to repeat later, there are exceptions). One of the present imperatives of the ACC is to increase the quantity of Chinese-language research and teaching about Australia. 


\section{Japan}

The Australia-Japan Foundation (AJF) is the best-funded of the bilateral bodies. It has the luxury of a permanent officer in Tokyo and its budget helps to maintain an Australian Resource Centre in the Tokyo embassy which is probably one of the best generaluse libraries for Australian studies outside Australia. It is used heavily by academics, students, members of the public and expat Aussies to catch up on the cricket score. It is now also heavily involved in remote, electronic requests for information, resource lending, etc. The AJF is part-funded by an endowment which means it does not have to rely solely on annual budget allocations from the Federal Government. It has its own Act of Parliament through which the foundation was established. The other important part of the program is a Chair in Australian Studies recently relocated in the Centre for American and Pacific Studies at Tokyo University (if this location sounds odd it is, in fact, a great benefit - Australian studies are not located within the English department or associated with language teaching! They are located within a research unit with a comparative and regional focus). This is a one-year rotating position.

After helping establish an Australian studies network in Japan a number of years ago, the program was languishing (and the Australian studies network was ageing) until a couple of years back when the AJF board put in place a new range of programs similar in many respects to the Chinese program, including book and translation awards and a scheme of fellowships and scholarships.

More recently, the AJF has moved to establish a serious electronic presence for Australian studies on its sophisticated web site, launching an Australian studies e-bulletin to inform Japanese Australianists of conferences, publications, grants and so forth.

There are two or three centres for Australian studies in Japan, but, unlike China, they are not a main focus for the foundation's programs. They have been focused largely on economic and trade issues, although the newest, at Waseda, has a more cultural focus. There is also a Japanese Australian Studies Association. 
One of the key differences between China and Japan is that in Japan Australian studies have (again, until recently) had a strong bias towards trade and economic issues. They have not been predominantly grounded in English or foreign-language departments and, therefore, the second major difference from China, they have been largely in the Japanese language. This has had its own limiting effects as there has been limited communication between Japanese and Australian Australianists and virtually none between Japan and other parts of global Australian studies!

Australian studies are, in fact, taught widely across the Japanese system, in one form or another: 83 universities, more than 170 courses, taught to about 15,000 students. But these figures exaggerate the effect as the courses are usually at a fairly junior level, usually as part of something else, often as a quick introduction for students about to go to Australia for study tours. The teaching is usually not something driven by research interests, not in the prestigious parts of the academy, often not part of a degree structure.

I've been focusing on the universities, but in fact the foundation's biggest successes have been in secondary and primary education where it has produced Australian studies kits. The secondary school kit has been placed in more than 11,000 Japanese schools and follow-up programs with teachers have ensured its widespread use. This breakthrough into the relatively closed Japanese education system is a major achievement.

\section{Australian studies trends}

This is the good news story. Australia can point to a remarkable achievement in the form of Australian studies centres and conferences, translations, courses and graduate students, all on the basis of modest financial support. In this sense we might say that Australia is punching above its weight (though not if we consider the importance of these countries to Australia's future).

The not-so-good news story is that despite all this activity, some of it going back more than a decade, the number 
of serious courses taught is still very small, the number of students proceeding through to graduate studies on Australian topics is miniscule, and, perhaps most serious of all, the amount of serious, substantial, international-quality research is, with only a few exceptions, negligible.

In other words, there has been a failure to produce a substantial body of up-to-date top-quality research from among Asian Australianists. I am very conscious of some exceptions, for example, some excellent papers from younger researchers at the last Chinese Australian studies conference so we might be able to predict a positive trend - but still, if we were summing up the picture so far, we'd have to say that very little research has been produced. Much of what has been produced has been at a very rudimentary level; and, despite the centres, the associations and the conferences, there is only a small number of active programs of research. And the research that is produced tends to have limited circulation, a limited influence, so that it is difficult to talk about a developing 'field' of Australian studies in these countries. There have been many books written in Japan about Australia, for example, but only a small number from a scholarly research perspective. And again, the problem of distribution has been significant.

Of course, there are clear reasons for this situation:

- There has until recently been little of what those in, say, Australian or American universities know as a 'research culture' in the humanities/social science areas;

- There has until recently been little research funding in the humanities/social science areas;

- The absence of a research culture is especially the case where Australian studies have emerged out of Englishlanguage teaching departments — which have been primarily devoted to language teaching;

- The problem of resources, of course, is perennial - there are few resources, few up-to-date sources of information, little access to current debates within Australian Australian studies, though this gap is decreasing with the use of electronic resources; 
- More serious is the lack of an audience for serious research, lack of opportunities for publication of serious research, and lack of distribution and promotion of books that have been published. Research languishes - it often doesn't seem even to reach other Australianists;

- The lack of institutional support for Australian studies (one reason why government support from the Australian end is crucial);

- $\quad$ Ageing Australian studies networks — older academics from a less research-oriented era - and difficulties, in an increasingly competitive education environment, attracting younger graduate students and academics towards Australian studies;

- Hierarchical staffing structures which make it difficult for young staff to move into new areas;

- America - that's where all the students want to go, even those who've done an Australian studies MA tend to want to use it to get an American $\mathrm{PhD}$;

- And, by the same token, Australia's 'minority' position — it is not a 'prestigious' culture in the academy as well as beyond in relation to the US or the main European nations; it is not seen as the originator of culture (one of the reasons we need Australian studies).

Where there is good research being done at graduate level it generally hasn't translated into new energies - new, younger academic staff - moving into the broader field of Australian studies and staying there. Perhaps this doesn't matter; I'm ambivalent myself. Perhaps exposure to Australian materials and methodologies at undergraduate and graduate level will, in most cases, be the most that can realistically be expected and achieves important aims in any case. But some of the best and brightest of the next generation of researchers do need to be 'Australianised' somewhere along the line.

One of the difficulties is that I don't think we will get any very serious attention from Australian governments - in lobbying for support for Australian studies overseas - until we are able to show that serious research is being produced. We are 
in danger of being caught in a catch-22: no serious funding until there is serious research, no serious research until there is serious funding. Frankly, there's little credibility at the moment, little that we could take to government and say 'look what's been achieved; give us a million dollars to do more of it'. I don't think an article or two on Judith Wright or Crocodile Dundee are going to help much here - though with the present government we might get a bit further with Les Murray.

Of course, Australian studies will keep finding a home in the English-language and literature departments, and so they should. Literature, cinema and other cultural forms will remain central to the enterprise. What we need to do is to push the boundaries of Australian studies out further, shift into new areas; but even more importantly try to think of new structures, new relationships, new funding mechanisms such that the emphasis shifts towards research, the research is up-to-date, and it is distributed, made accessible, built into teaching and research programs.

Of course, I have a wish list. I would like to see an expanded DEST-run scheme of graduate scholarships specifically designated for studies of Australia - not just study in Australia. A small number, as low as five a year from the Asia-Pacific region, could make a real difference. A Colombo Plan for the 21st century, perhaps, with an explicit Australian studies twist. I would also like to see more funding directed to commissioned research, probably through competitive bidding, including, but not limited to, areas where the Australian side can set the research priorities. But the point remains research by those offshore (in collaboration, of course, where appropriate) for their local and, wherever possible, for international audiences. I'd like to see a dedicated transnational program not only for bringing Asian Australianists to Australia but bringing people from different countries together. I would like to see some serious, coordinated investment in web-based and other resources for overseas scholars studying Australia - the online Japaneselanguage Australian studies bulletin is an important model. 


\section{Ideas of Australia}

Despite the positive signs of new activity within the DFAT bilateral bodies, ${ }^{3}$ and the pockets of Australian studies activity across the Asian region, the big picture is a pretty disheartening one. Research, in particular, has been at a minimal level. There is precious little evidence of Australian studies research that could, for example, impact on the way overseas governments and bureaucracies think about Australia. In fact, if we think of the level of Australian studies knowledge in most places in the region, it is positively scary to imagine the quality of information that overseas governments are getting about anything other than trade figures. The stereotypes of 'East versus West' are alive and well, even within Australian studies circles.

In this respect, on the basis of my own overseas experience teaching Australian studies and developing Australian studies centres, I argue strongly that Australian studies overseas should not be thought of — or sold as - yet another case of 'area studies'. This is mostly how Australian studies are perceived when they are parachuted into foreign universities. I'd want to make the case, instead, for seeing Australia, not as a vehicle for specialisation but for internationalisation. In other words, Australian studies promoted and pursued as part of regional studies, comparative studies, international studies, global studies — the emphasis will be different depending on the local context. Of course, we still want experts, specialists, researchers, centres, but how the project is conceived from the ground up makes a difference to how we might also conceive of these experts and specialists.

For many people working in overseas universities this is a matter of beginning from where they are — from existing research or teaching interests in American, British or Canadian societies, international law, foreign policy, social policy, women's studies and so forth — rather than attempting the leap into a whole new speciality. The important objective is not so much to produce full-time Australianists as to get Australia 'into the frame', to get it into the conversation, to incorporate it into comparative, regional, international frameworks - and, 
in many ways, that means emphasising what it shares with other nations rather than flogging its 'uniqueness'.

The way to conceive of the offshore development of Australian studies is not to focus on Australia in isolation or to imagine that we are beginning from nothing, but rather to think of Australia as belonging in a network of potential points of comparison and contrast - with the US and Europe in some dimensions, other colonial settler colonies in another, other Asia-Pacific nations in another and so on. The aim is to have Australia take its place naturally in the frameworks of comparison in whatever the field is - literature, geography, anthropology, public health, environmental policy and so on.

From this perspective we have to be prepared to allow for the possibility that the best 'Australian studies' won't always come from within the field explicitly named as such — this is certainly the case in Australia itself. Allowing this also allows us the possibility of seeing Australian studies as linked to the idea of Australia as a place ideas come from - not just products or tourists. Australia is a significant exporter of research, theories, knowledge and culture (to return to my opening theme), an originator, in areas as diverse as women's studies, cultural studies, environmental studies, international law, indigenous studies and, of course, Asian studies. Australian studies need to be open enough to let in all of these developments.

From another perspective, Australian studies are a massively under-utilised resource - under-utilised, that is, by Australian governments, and perhaps even by our own universities supposedly committed to the internationalisation of education and promoting a positive image of the nation. 'Studying in Australia' is almost completely disarticulated from 'studying Australia' - certainly there is no structured program to encourage that further step.

The Asian Accounts of Australia Project itself poses some interesting questions about how the research it has generated could feed back into Australian studies in China and Japan and elsewhere in the region. At first I thought 'minimally'; after all, isn't our primary task that of increasing 
the overseas study of Australian materials? But on reflection, what this research ought to encourage is critical self-reflection on the production of knowledge about Australia within the countries and cultures concerned. In fact, this is a dimension almost entirely lacking in Australian studies in Asia at present: Australia is 'there', China or Japan is 'here'. Much of the work is still posited in terms of opposition - China vs. Australia, Australia vs. Japan, in a more or less predictable pattern of binaries. But as far as I'm aware there has been little or no work done on the recent history of how knowledge about Australia in China or Japan has been produced, little dialectical understanding of the process or sense of an internal dialectic. Little work has been done on China's Australia or Japan's Australia, work I see as being as much a part of Australian studies - of a discipline examining its own groundings - as learning those trade figures or trying to pin down mateship or the bush legend once and for all. 


\section{Footnotes}

$1 \quad$ FitzGerald, Stephen. 1997. Is Australia An Asian Country? p.63. Sydney: Allen \& Unwin.

2 For a report at the end of this project, see Australian Studies Offshore: Time to Start Again? Crossings. Vol. 3. No. 1. August 1998. http://pandora.nla.gov.au/tep/13231

3 New Australian studies programs are being pursued by the Australia-Indonesia Institute and the Australia-India Council. 